\title{
Rectal pocket syndrome following PPH and rectosigmoid resection
}

\section{Pescatori}

Received: 2 March 2010/ Accepted: 16 March 2011/Published online: 9 June 2011

(C) Springer-Verlag 2011

A 55-year-old woman had a PPH performed for rectal internal mucosal prolapse and rectocele. After surgery she continued to suffer from mucosal prolapse and obstructed defecation. In an attempt to remove the prolapse a second PPH was perfomed 2 years later. This was complicated by rectal lumen obliteration which was treated by a low anterior resection. Four years later she continued to have evacuatory disorders and proctalgia. On exam she was found to have a $5 \mathrm{~cm}$ deep rectal diverticulum with entrapped fecaliths at what appeared to be the site of the first PPH (Fig.1). She underwent laying open and

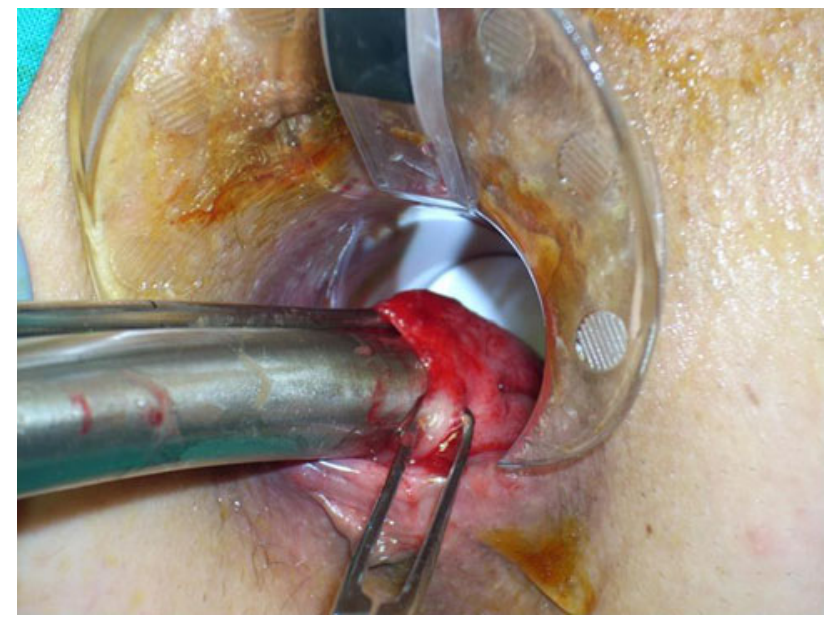

Fig. 1 The rectal diverticulum probed by a $16 \mathrm{~mm}$ Hegar dilator

M. Pescatori ( $\square)$

Coloproctology Unit, Ars Medica Hospital, Rome, Italy

e-mail: ucpclub@virgilio.it

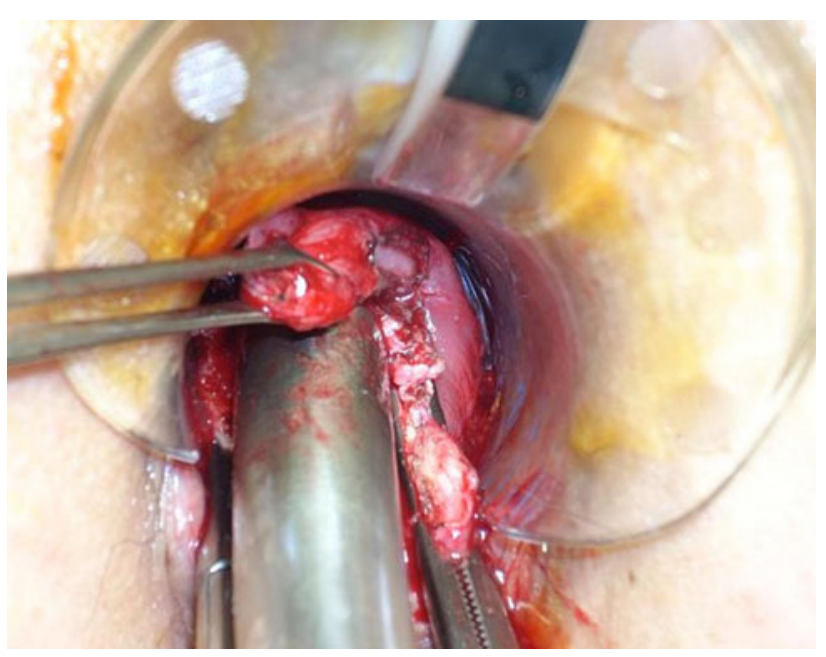

Fig. 2 The pocket is being laid open

marsupialization of the diverticulum with removal of several retained staples (Fig. 2). The patient is symptom-free 6 months after surgery. 